\title{
Employee Empowerment and Differentiation in Companies: A Literature Review and Research Agenda
}

\author{
Prof. Dr. Nihat KARAKOC \\ Prof. Dr., Faculty of Engineering and Architecture, \\ Department of Industrial Engineering Department, \\ Balıkesir University, Turkey \\ Tel: 02666121194 (357) nkarakoc@ balikesir.edu.tr \\ Dr. Ayse KUCUK YILMAZ (Corresponding author) \\ Asst.Prof.Dr.; School of Civil Aviation, \\ Anadolu University, 26470 Eskisehir, Turkey
}

Tel: 02223350580 (6962) akucukyilmaz@ gmail.com

\begin{abstract}
Similar goods and services, which increase in the market, have decreased the market share of companies. Therefore, it has put pressure on companies towards product differentiation and new markets establishment. Since it can cause companies to gain differentiation capabilities, human resource has transformed into the strategically competitive element of a company.

Employee empowerment causes to benefit from different skills and capabilities of human resource at maximum degree. Therefore it plays an important role in customer and employee satisfaction.
\end{abstract}

In this study, employee empowerment concept and the effects of employee empowerment on 


\section{Macrothink

differentiation process in companies have been investigated. The probable contributions of employee empowerment on differentiation process have been determined, from the point of view of speed, prevalent participation, team responsibility, differentiation alternatives, organizational learning, employee qualifications, creativity, motivation and job satisfaction. In order to obtain those contributions, some proposals related to conditions of empowerment that are necessitated in companies, have been presented. This article is presented as our initial work to our planned future work which is entitled as "risk management based approach to employee enpowerment and differantiation process.

Keywords: Differentiation, Empowerment, Human Resources Management, Innovation, Risk Management. 


\section{Macrothink}

\section{Introduction}

Strong wind of change have forced companies, which have been limited to local and national markets with their limited environmental conditions, to move to big arenas of Olympics where competition is at a global level. The competitors are numerous and competition is quite tough under the conditions of these new competition areas. In this arena there is no place for protectionism, doping and any irrational behaviour.

Under these conditions companies have to design and shape their organization structure, management understanding, company competences and outputs according to new competition conditions in order to compete. The conditions such as customers' demand, environmental pressure, quality standards etc. and their partnership, have caused tendency to transform similar characteristic make-up of the companies under the same market conditions (Ataman, 2003: 16; Koçel, 2003: 362).

Because of this tendency, the market shares and the profit margins have been decreased by increasing the pressure on the sales price due to increase of similar products in the same market and the priority given to similar products with the minimum price. (Kırım, $2005: 6$ ). The most effective way to save companies from the whirlpool price competition on the basis of 'similarities', which destroy the companies rapidly, is differentiation (Argüden, 2006). In other words, it is the acquisition of skill of transforming the products into shapes which can fulfil the new need and taking them out of the area of multi-competitors and help them gain sustainability.

The 'Human Resource' of company, different from components of others is of the type that cannot be copied/imitated. For this reason, it has a strategic role to be effective to gain differentiation competence of company and to differentiating. However, human resource in company has to meet the requirements for this role in terms of qualifications and power in order to take over such a role.

Employee empowerment, which is one of the concepts of new management, gaining from different knowledge, skill and talent of the employees at the highest level, plays an important role in internal and external customer satisfaction.

In this study, the role and importance of employee empowerment on differentiation process and employee empowerment concept have been investigated and supported by risk management based approach.

\section{Employee Empowerment}

Employee empowerment, which came up in 1990s, is known as one of the new management concepts (Hanold, 1997; 2002). However, when the relevant literature is analysed, this concept is understood to have a longer history than previously thought (Nykodym et.al., 1994: 
45; Wilkinson, 1998: 42). With its roots Human Rights Movement' of 1950 and 1960s, empowerment has rather closely related to the various concepts and techniques designed to democratize the work-place (Elmuti, 1997: 233). As a matter of fact empowerment was given place in the publications of Pre-1990 that discussed topics such as work enrichment, participative management, employee motivation, total quality -control, individual development, quality circles and strategic planning. Without any doubt, perceptible increase in the number of articles related to employee empowerment was seen after 1990s (Honold, 1997: 202)

Empowerment is one of the most effective ways of enabling employees at all levels to use their creative abilities to improve the performance of the organization they work for, and the quality of their own working life. Employee empowerment is a kind of the risk management process whereby a culture of empowerment is developed information - in the form of a shared vision, clear goals, boundaries for decision making, and the results of efforts and their impact on the whole is shared competency in the form of training and experience is developed; resources, or the competency to obtain them when needed to be effective in their jobs, are provided; and support in the form of mentoring, cultural support, and encouragement of risk-taking is provided (Chaturvedi, 2008).

\subsection{Definition}

Fundamental reason to difficulty in making a definition is a multi-dimensional concept that empowerment involves a dynamic process in a dynamic environment and many elements that have roles in different phases of this process (Robbins et. al., 2002: 420). When author's perception is added to this from different angles and when different languages are added for different dimensions, a number of definitions emphasizing different dimensions of concept have come up (Ugboro \& Obeng, 2000: 249). The examples of definition that emphasize the purpose, process and different dimensions of employee empowerment are as follows:

- The examples of definition that emphasize the purpose:

According to Kanter (1977), empowerment is to give power to people who are weak in organizations (Ugboro \& Obeng, 2004: 249) Empowerment is spreading the administrative responsibility to all the places in the organization (Cunnigham \& Hyman $1999 ; 193$ ). Empowerment is to give more authority to employees in organization in management of work (Pearson \& Chatterjee, 1996 : 17). It is to bring employees to the position of owners of work (Koçel, 2003: 414). According to Foster, Fishman and Keys (1995), it is a process of bringing an individual or a group to a position that he/she can affect events and the results (Hanold, 1997: 202).

- The examples of definition that emphasize the process and dimensions of empowerment

According to Rothstein (1995), Empowerment is "an act of building, and increasing power 
through cooperating, sharing and working together'(Honold,1997:202).

According to Pet and Miller, employee empowerment is the concept of enabling subordinates to have the authority and capacity to make decisions and to act for the organization in order to improve both individual motivation and organizational productivity (Elmuti, 1997:233).

According to Zemke and Schaaf (1989), employee empowerment means turning the "front line" loose, and encouraging and rewarding employees to exercise initiative and imagination.

A more operational-level and process-oriented definition of empowerment was offered by Bowen and Lawler. They define empowerment "as sharing with front-line employees the information about an organization's performance, information about rewards based on the organization's performance, knowledge that enables employees to understand and contribute to organizational performance, and giving employees the power to make decisions that influence organizational direction and performance"(Ugbaro and Obeng, 2000:249).

According to Murrel, empowerment is an act of building, developing and increasing power by working with others, which he terms as "interactive empowerment" and having the ability to influence one's own behaviour, which he calls as "self empowerment"(Honold, 1997:202).

According to Conger and Kanungo (1988), empowerment is a process of enhancing feelings of self- efficacy among organizational members through the determination of conditions that foster powerlessness and through their removal by organizational adjustments (Simit \& Mouly, 1998:70).

Another definition of the same author is that 'It is a relational construct based on superior-subordinate authority sharing and a motivational construct that satisfies an individual's desire for self-determination and self-efficacy. (Elmes et.al., 2005 : 5).

Spreitzer, after an extensive review of literature, has been determined of having defined two different perspectives of empowerment within a business context, as the relational and psychological perspective. Relational empowerment has been referred to as top-down processing as well as mechanistic. It is the belief that empowerment occurs when higher levels within a hierarchy share power with lower levels within the same hierarchy. On the other hand, according to the psychological perspective empowerment focuses on the employee's perspective of empowerment. Psychological empowerment, also known as organic or bottom-up processing, maintains that empowerment is achieved only when psychological states produce a perception of empowerment within the employee (Mattews, 2003 : 297).

If there is a need to make definition in the framework of this study, the employee empowerment is a process to satisfy the internal and external customers which increases the employees' authority in the work and their knowledge, skill, opportunities, self-confidence 
and desire related to their authority; also it is a process of providing perception related to this increase.

\subsection{The Purpose, Content and Meaning of Empowerment}

The purpose of empowerment is to increase the authority, knowledge, motivation related to the work of employees; therefore to enhance the contribution of employees to company and customers' satisfaction (Jhul et al., 1997: 103), at the same time to increase the self respect, confidence and loyalty towards company (Wilkinson, 1998; 40). In short, the aim is to increase the satisfaction of the internal and external customers (ugboro \& obeng, $2000: 249$ )

The Contents of empowerment: As the empowerment can be done at individual level, it can be done at a team level which in size contains all employees in a process, in a unit or in a company (Honold, 1997: 203).

The individuals to be empowered in the organization are employees found at the lowest. However employees get power (authority) from their superiors in hierarchy basically (Elmes et.al., $2005: 5$ ), according to the interaction, they obtain it from other workers and according to the skill and will of getting power, they get it from themselves. (Honold, 1997: 203)

Hence we can talk about three types of power sources.

\subsection{Empowerment Dimensions}

An empowerment from top to bottom or from managers to employees means giving power to employee at four dimensions that consists of "authority", "specialization", "resource" and "personality". Authority is the power dimension which makes up the essence of empowerment or the body. The other power dimensions are the characteristic which uses authoritative power effectively, supportively, easily and complementary. The authority dimension of empowerment, the right to take decision related to the meaning, the environment and content of the work done by employees; the specialization dimension, the knowledge and skill of decision making/application; the resource dimension, being the most important sharing of knowledge, the possibility of attaining and using resources related to their work; the personality dimension, however, are the self-confidence to use the authority and motivation (Koçel, 2003: 417).

When the empowerment in the organization is seen from down to up or when seen from the employee's point of view, it is seen as something perceived by them or the psychological dimension can be seen. Some of the main factors that determine the empowerment perception are as follows: (meaning) finding the work done by the employee as meaningful(important); (competence) to feel oneself as sufficient, (self-determination) the possibility of making choice and (impact) the degree of effectiveness perceived over certain results in the work process (Robins et al., 2002 : 442, Ugboro \& Obeng, 2000 : 249). 


\subsection{Empowerment Variables}

The qualities of employees, who will be empowered, are important organizational and managerial atmosphere are the principal variables of empowerment. They can be summarized as follows (Nykodym et al., 1994: 45; Koçel, 2003: 417):

- The employees not being desirous to development, not having critical thinking skills, not being open to change, not having high self-confidence and not being favourable to co-operation (Ceylan, 2002 : 113) ; the level of feeling important, self-sufficient, efficient and having authority at work. (Robbins et al., 2002 : 421)

- Whether the organization is flat and whether it has organic structure; performance appraisal, feedback, rewarding (Born \& Molleman ; 1996 : 30), human resources procuration, protection (King \& Erhard, 1997 : 139), training and communication system; the level of authority given to employee by the work definition;

- The encouragement and motivation to decision making by managers to their subordinates; creating a participation culture and creation of a sharing vision; emphasizing flexibility and autonomy, sharing information, inspiring confidence and the level of managers' trust to their subordinates.(Mattews, $2003: 299$ )

\subsection{Empowerment Strategies}

These are some of the main strategies which can be benefitted in employee empowerment (Ugboro \& Obeng, 2000 : 249)

- Changing of work definition: The content of the work (to increase activities the required of work) or authorization by widening the meaning and framework (determining new jobs which suitable for vision and mission of organization); by enrichment method, to increase authority of employee and meaning of job.

- By enlargement the span of control, to facilitate authority transition from managers to subordinates.

- By increasing the qualification of the managers (with training programmes, recruitment system), to facilitate and encourage authority sharing manager's with their subordinates ( empowerment from external resource)

- By increasing qualification of employees( with recruitments and training programmes), to support and facilitate effective use of authority; to increase and support confidence in the managers for the sharing of authority; to encourage the subordinates to take over authority (empowerment from internal resource) 
- By applying organization at the team basis, on the basis of co-operation and interaction, to provide empowering of employees, improving and increasing (Hanold, $1997: 203)$

- By restructuring the work process, to increase influence on the work process and it's on result of employee (Hanold, 1997: 203).

- By benefitting from performance appraisal system, to help employees foresee their weak features and to increase their power in the areas they use their authority.

- With rewarding system based on performance to motivate the employees for using authority getting and sharing knowledge

\section{The Effects on the Differentiation Process of the Employee Empowerment}

In today's competitive work conditions, existence of a strong connection between the continuation of existence of company and the competences that provide the satisfaction to the customers, between gaining this competence and modern management philosophy and practices, this theory seems to be getting more obvious. Differentiation has become a vital competence that companies should possess in their competitive conditions. Employee empowerment is a philosophy and arrangement that will help companies gain this vital competence.

Differentiation, is a risky process that provides changes or innovation in the process, outputs, product marketing and after sales service of company for the purpose of gaining/getting extra value which affect the customer's priority for company and its products.

In the light of this definition, principal points which should be emphasized related to differentiation are as follows:

- Differentiation is a process which involves metamorphosing, changing and innovating.

- Differentiation is not a one time action but rather a process which is repeated systematically

- Differentiation is a process where with the way of taking into consideration the permanent and systematic risks/ and opportunities supporting the companies in getting harmony to changing environment and successful in the global competitive environment. Differentiation is risky process; risk management based approach can be usefull to achieving aims by differantiation.

- The purpose of differentiation is to gain extra value that can affect the customers' preferences to company and its products

- Differentiation is based on a communicative system where the internal and external dimensions of company work co-operatively. 
- Differentiation is based on the philosophy of learning organization and on management philosophy that is supporting, developing and encouraging creativity

The following are mainly differentiation fields (Kırım, 2007: Accenture, 2007):

a. Management philosophy : This is an area of differentiation of the managerial philosophy and application

b. Input: All the raw material, semi finished goods, the inputs in the form of human resource qualifications are differentiation areas.

c. Processes: All processes which are related to business management functions are areas of differentiation (The procurement of inputs, the processes that transforms these inputs into outputs, the marketing processes, the management process, human resources management process, etc.)

d. Outputs: The outputs of all the process of company and the outputs in the form of goods or services presented to customers are differentiation subjects.

The effect on the differentiation process of employee empowerment can be summarized as follows:

1. The shortening of differentiation process: With empowerment, employees attain the power to take decisions related to their work directly. Hence changes that answer customers demand/need (the structure of products, packaging, condition of payment etc.,) are done directly in a short time by the employees doing the work.(Jhul et.al., 1997 : 103) Hence differentiation process to increase customer's satisfaction gets shortened.

2. To create common responsibility philosophy in the differentiation: Employee empowerment, is giving authority to managing of self work to employees and thus to spread Deming Cycle of (planning, application, control, precaution) which is constituted of fundamental of 'Total Quality Management philosophy' to lower organizational level.(Jhul et al., 1997 : 103 ; Prybuto \& Kappelman; 1995 : 16). The taking over of the differentiation responsibility by every employee of company of their purpose of work, their inputs, the process, the results by continuously improving them; the differentiation of company is not limited to some units or individuals but rather a team work that spreads to the whole company and can be provided/done by a team concept and responsibility.

3. The multiplying of the differentiation choices: Employee empowerment is to benefit from all employees in company, as level of their authority in the work done by employees, gain from different competence and point of view to maximum. Thus, it can provide important richness in differentiation choices to many employees who have different competences and they are given opportunity to take role in the process of differentiation 
4. To constitute an available employee infrastructure to the differentiation process: In order to have employees empowerment there is a need for employee qualifications, such as being open to development, having the skill of critical thinking, having high self confidence. These qualifications constitute the infra structure of the employees available in the process of differentiation.

5. Provision of Organizational Learning support: Empowerment at specialization dimension is empowerment dimension that the supportive and simplifying of using effective authority given to employees. Specialization of employee is expected by following news, scientific publications, meetings and researches relevant to work done continuously. The management also is to support, facilitation and encouragement for learning and self development efforts relevant to work of employees through different means, methods and opportunities. For example, the use of wage system based on skill, the use of 'self development', 'the following of the developments related to work', 'Selfdevelopment types of criteria for performance appraisal, supporting employees through participation in scientific meetings like seminars and conferences and so on. This learning system which works throughout the organization is a strategic element of differentiation process.

6. The increasing of the creativity: In the empowerment, the working of the employees in meaningful, important jobs where they feel sufficient is a pre-condition. This application is an indispensable basic element of creativity that constitutes most important source to support differentiation.

7. The increasing of Motivation and Work satisfaction: Empowerment provides an atmosphere where employees feel efficient and as owners of the work; serving a need for self-actualization and accomplishment of employees. This atmosphere increases employees' self respect, work motivation and work satisfaction. (Robins et al., 2002: 442; Jhul et al., 1997: 103; Chu, 2003: 507). By being in the management of work, employees would have high job satisfaction, which will eventually facilitate making changes that will increase customers' satisfaction

\section{Conclusion}

Globalization, changing competition conditions and increasing of similar products cause narrowing of market share of the companies and forces them to create new markets by product differentiation. Since it can cause companies to gain differentiation capabilities, human resource has transformed into the strategically competitive element of a company. Employee empowerment causes to benefit from different knowledge, skills and capabilities of human resource at maximum degree Therefore it plays an important role in customer and employee satisfaction. 


\section{Macrothink}

In this study, the role and importance of employee empowerment on performance of differentiation process in companies have been investigated. The probable contributions of employee empowerment on differentiation process have been determined. These can be listed as follows:

1. The shortening of differentiation process.

2. The creation of common responsibility philosophy in differentiation.

3. Multiplying of Differentiation choices.

4. To constitute an infrastructure which has qualifications required for differentiation process.

5. Provision of Organizational learning support.

6. Increasing creativity

7. Increasing motivation and work satisfaction

For the employees to make contribution in the process explained above, they should not be insufficient in terms of authority. The managers should act with the idea that by empowerment at authority dimension to their subordinates doesn't mean that there would be any decrease in their powers but rather their powers will be increased further. This is because the managers will always have more power/authority over their subordinates and if/when they use them more effectively, they will always have more power and more time.

This study can be a systematic starting point, a source of inspiration and motivation for new researches in understanding the condition in application of the probable contribution of employee empowerment to differentiation process.

We are working on "Risk Management based approach to the differentiation process" as future work. The article is assumed as initial work to this future work. We aim to contribute the human resource management via employee enpowerment and differentiation by this article and our future works.

\section{References}

Accenture (2007), Tedarik Zincirinde Inovasyon. (http://www.accenture.com.tr.) [10.11.2007] Argüden, Y. (2006). Yeni İş Geliştirmek İçin Yapmanız Gerekenler. (http//www.arge.com.tr). [31.07.2007]

Ataman, G. (2003).Örgüt Tasarımında Yeni Tekniklerin Yayılım dinamikleri. Öneri,5(19), 13-19.

Born, L. \& Molleman, E. (1996). Empowerment and Rewards: a Case Study. Empowerment in Organizations, 4(3), 30 -33.

Ceylan, A. (2002). Çalışanların Güçlendirilme Algıları Üzerine Tuzla Bölgesindeki Ticari Bankalarda Bir Araştırma. Öneri, 5(17),113 -120. 


\section{Macrothink}

Chaturvedi, V. (2008). Employees Empowerment: A key to intrinsic motivation, Management Articles, Articles and Papaers by Faculty of Management Institutes, 2008, http://www.indianmba.com/Faculty_Column/FC781/fc781.html,

Chu, K.F. (2003). An Organizational Culture and the Empowerment For Change in SMESs in the Hong Kong Manifacturing Industry. Journal of Materials Processing Technology, 139(1), $505-509$.

Cunningham, I. \& Hyman, J. (1999). The Proverty of Empowerment? A Criticak Case Study. Personnel Review, 28(3), 192- 207.

Elmes, M.B. ; Strong, D.M. \& Volkoff, O. (2005). Panoptic Empowerment and Reflective Conformity in Enterprise Systems-Enabled Organizations. Information and Organization, 15(1), 1- 37.

Elmuti, D. (1997). Self-managed Word Teams Approach: Creative Management Tool or a fad. Management Decision, 35(3), 233- 239.

Honold, L. (1997). A Review of The Literature on Employee Empowerment. Empowerment in Organizations, 5(4), 202- 212.

Juhl, H.J.; Kristensen, K.; Dahlgaard, J.J. \& Kanji, G.K. (1997). Empowerment and Organizational Structure. Total Quality Management. 8(1), 103 -111.

Kırım, A. (2005). Farklı Olan Kazanır. 8. Baskı İstanbul: Sistem Yayınları. S. 6.

Kırım, A. (2007), Emrinize Amade İnnovasyon Türleri. (http://www.fedtraining.com.tr) [Erişim tarihi: 31.07.2007]

King, A.S. \& Ehrhard, B.J. (1997). Empowerment the Workplace: A Comminment Cohosion Exercise. Empowerment in Organizations, 5(3), 139 -150.

Koçel, T. (2003). İşletme Yöneticiliği. 9. Baskı. İstanbul: Beta Yayınları.

Mattews, R.A..; Diaz, W.M. \& Cole, S.G. (2003). The Organizational Empowerment Scale. Personnel Review, 32(3), 297 -318.

Nykodym, N.; Simonetti, J.L.; Mielsen, W.R. \& Welling, B. (1994). Employee Empowerment. Empowerment in Organizations, 2(3), 45- 55.

Pearson C.A.L \& Chatterjee, S.R (1996). Implementing Empowerment Through Subunit Clusters: a Western Australian Case Study. Empowerment in Organizations, 4(3),16- 25.

Prybuto, V.R. \& Kappelman, L.A. (1995). Early Empowerment Creates Productive Outcomes During an Organizational Transformation. Work Study, 44(7), 15-18.

Robbins, T.L.; Crino, M.D \& Frendal, L.D. (2002). An Integrative Model of the Empowerment process. Human Resource Management Review, 12(3), 419- 443.

Simith, A.C. \& Mouly, V.S. (1998). Empowerment in Neww Zealand Firms: İnsights From two Cases. Empowerment in Organizations, 5(4), 69- 80.

Ugboro, I.O. \& Obeng, K. (2000). Top Management Leadership, Employee Empowerment, Job satisfaction, and Customer Satisfaction in TQM Organizations: an empiricak study. Journal of Quality Management, 5(2), 247- 272.

Wilkinson, A. (1998). Empowerment: Theory and Practice. Personnel Review, 27(1), 40- 56. 